\title{
P-pulmonale by ECG Finding
}

National Cancer Institute

\section{Source}

National Cancer Institute. P-pulmonale by ECG Finding. NCI Thesaurus. Code C71041.

An electrocardiographic finding suggesting underlying hypertrophy or dilatation of the right atrium. Electrocardiog raphic criteria used for the diagnosis of right atrial abnormality may include a peaked p wave greater than 2.5 millimeters in amplitude in the inferior leads. 